\title{
Fuzzy Logic based H-bridge STATCOM Controller to compensate Unbalanced Voltages
}

\author{
G Mahesh ${ }^{1}$ | P Ankineedu Prasad ${ }^{2}$
}

1PG Student, Dept of EEE, Vikas College of Engineering, Vijayawada, India

${ }^{2}$ Associate Professor\& HOD, Dept of EEE, Vikas College of Engineering, Vijayawada, India

To Cite this Article

G Mahesh and P Ankineedu Prasad, "Fuzzy Logic based H-bridge STATCOM Controller to compensate Unbalanced Voltages", International Journal for Modern Trends in Science and Technology, Vol. 06, Issue 07, July 2020, pp.:135-139; https://doi.org/10.46501/IJMTST060721

\section{Article Info}

Received on 17-June-2020, Revised on 28-June-2020, Accepted on 15-July-2020, Published on 22-July-2020.

\section{ABSTRACT}

In this paper a new method four-leg topology is suggested for shunt compensation, the H-bridge multilevel converters based on the half-bridge converters, to achieve higher performance as a STATCOM in a distorted and unbalanced medium-voltage large-current system. Further, an extended Fuzzy based STATCOM is proposed in order to manage more accurate compensation for high-power applications. Both proposals can be controlled for various purposes such as reactive power and unbalance compensation, voltage regulation, and harmonic cancellation. One interesting application for the Fuzzy logic based STATCOM could be the improvement in power quality and performance of the electrified railway traction power supply system. Both the H-bridge based STATCOM along with their proposed control strategies were simulated.

KEY WORDS: Harmonics, medium-voltage large-current modular multilevel converters, unbalanced compensation, Fuzzy Logic.

Copyright (C) 2020 International Journal for Modern Trends in Science and Technology

DOI: https://doi.org/10.46501/IJMTST060721

\section{INTRODUCTION}

MODERN medium-voltage distribution systems supply nonlinear loads such as single-phase ac traction systems. These loads make the network to operate under undesired conditions, i.e., distorted, uncontrolled reactive power and significant unbalance enforcement [1], [2]. Therefore, these associated in-evitable issues ought to be simultaneously resolved to achieve acceptable power quality level. Meanwhile, mitigation of all these power quality problems by means of a single compensator is a challenging task in a medium-voltage network [3],[4].A full-bridge cascaded converter (FBCC) could be directly connected to a medium-voltage network [5], [6].
However, the FBCC has been established as the most preferred solution for managing reactive power in distribution systems, improving the power quality in the medium-voltage high-power industries. Un-like diode-clamped multilevel converters (DCMC) and flying-capacitor-clamped multilevel converters (FCMC), the FBCC introduces lower total losses along with higher reliability [7], [19].Meanwhile, they have their restrictions when operating under distorted unbalance situations in a medium-voltage network compared to those of the DCMC and the FCMC [3]-[8]. In the mean time, a three-phase FBCC, connected in delta or star type, is unable to fully compensate the source currents when the un-balanced loads containing harmonics. A delta-connected FBCC cannot generate zero sequence components flowing 
through the fourth neutral-wire. Also, balancing an unbalanced load using a star-connected FBCC is faced with some complications. Assume that a star-connected FBCC-based STATCOM is balancing three different active powers supplied by the source. Then, a certain average real power has to either flowing into or out of individual series connected full-bridge converters (leg). This results in either dc-link build-up or discharge of capacitors in that leg. In other words, the unbalanced currents of the star connected FBCC imposes unequal active power exchange by the FBCC legs. This makes the dc voltage balancing for the storage capacitors in all three legs much complicated [9].

The idea of modular multilevel converters (H-BRIDGE) was first introduced by Marquardt for medium-voltage applications [10].These converters consist of two similar parallel half-bridge cascaded converters (HBCC) per phase (three-phase in star-connected configuration). Due to the modularity of these converters, they are very attractive for high voltage dc transmission (HVDC), flexible ac transmission systems (FACTS), and medium-voltage drives [11], [12]. The main advantage of ap-plying the H-BRIDGE as a STATCOM [13] is that they could operate under unbalanced and distorted voltages and currents properly, while voltages of the dc-link capacitors remains balanced [9].

Hence, this paper proposes a new type of the H-BRIDGE topology as a STATCOM in order to achieve full compensation of MV-LC loads, i.e., harmonic elimination, reactive power optimization and in particular balancing the three or four-wire systems. The full compensation using the proposed STATCOM is achieved without any coupling transformer for MV-LC applications (high-power). Nevertheless, available power semiconductor technology may impose limitations due to the voltage and current ratings, losses, and switching frequency. Hence, here the H-BRIDGE is proposed that is composed of parallel connection of multiple H-BRIDGE per phase in order to deal with large-current requirements. There are two main differences between the H-BRIDGE and just parallel connection of H-BRIDGE: 1) two or more H-BRIDGE share the common dc-link (positive and negative common points); and 2), the presence of the coupling inductors that lowers down considerably the circulating current between them. The H-BRIDGE produces higher quality waveforms for the network compared to the H-BRIDGE, reducing the conductive electromagnetic interference concerns in large-current applications. Also, paralleling multiple H-BRIDGE improves reliability, performance, and efficiency of the overall system, making it more flexible. This paper is initially focusing on description of the H-BRIDGE-based STATCOM, both the proposed power circuit and control algorithms.

\section{H-BRIDGE-BASED STATCOM PROPOSITION} composed of two parallel connected complementary $\mathrm{HBCC}$ as shown in Fig. 1. Each star-connected HBCC has either three or four similar legs (cascaded HBM). While one HBCC has a negative common point (NCP), the other one has a positive common point (PCP). Both the NCP and PCP are float. To compensate a three-wire distorted load, the converter can be composed of two three-leg complementary HBCC. The number of levels, in a general $(n+1)$-level H-BRIDGE, is defined by the available $n$ identical HBM cascaded in each leg. Then, all $(n+1)$-level legs are connected to the network using an inductive filter (LF).

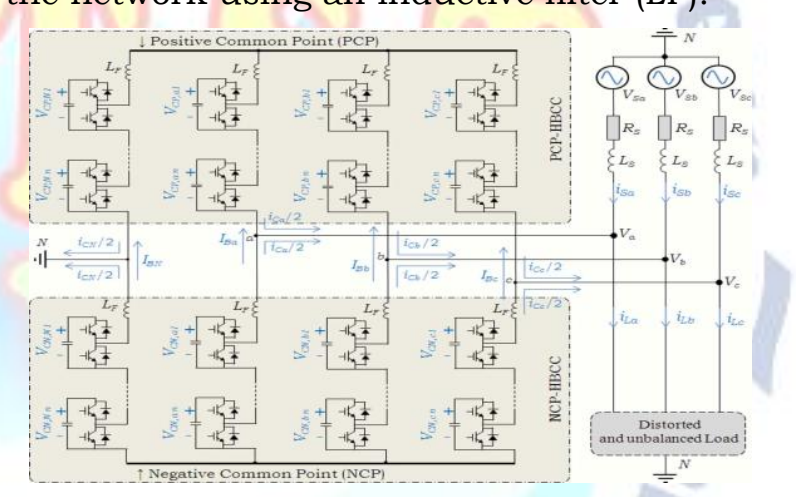

Fig 1: Proposed STATCOM circuit

Voltage regulation of the dc-link capacitors is achieved with-out any additional connections or energy transfer circuits to the associated HBM. Considering the detailed picture of the proposed H-BRIDGE in Fig. 2, each HBM is capable of producing either $\mathrm{V}_{\mathrm{Cm}}$ (the $\mathrm{mth}$ dc-link capacitor voltage) or zero at any given instance. Thus, the resultant voltage of $\mathrm{n}$ cascaded HBM varies within $\left[0, V_{\mathrm{DCM}}\right]$, where $\mathrm{V}_{\mathrm{DCM}}=\mathrm{nV}_{\mathrm{Cm}}$. Hence, all phase-to-phase voltages on each HBCC are obtained through a KVL over two identical opposite polarity legs (each leg controlled independently) by ignoring the inductor voltages (see Fig. 2). In other words, the voltage between any two phases of an $\mathrm{HBCC}$ can be adjusted between $+\mathrm{V}_{\mathrm{DCM}}$ and $-\mathrm{V}_{\mathrm{DCM}}$, $-\mathrm{V}_{\mathrm{DCM} / 2}$. Although the voltage across a leg has a dc component, there exists no dc component on any phase-to-phase voltage of an HBCC. To enable 
compensation of inductive loads, the value of $\mathrm{V}_{\mathrm{DCM}}$ must be chosen greater than peak-to-peak amplitude of the line voltage [14]. It should be noticed that both legs of a pair-leg are controlled such that supplying constantly one half of the total current per phase for the H-BRIDGE.

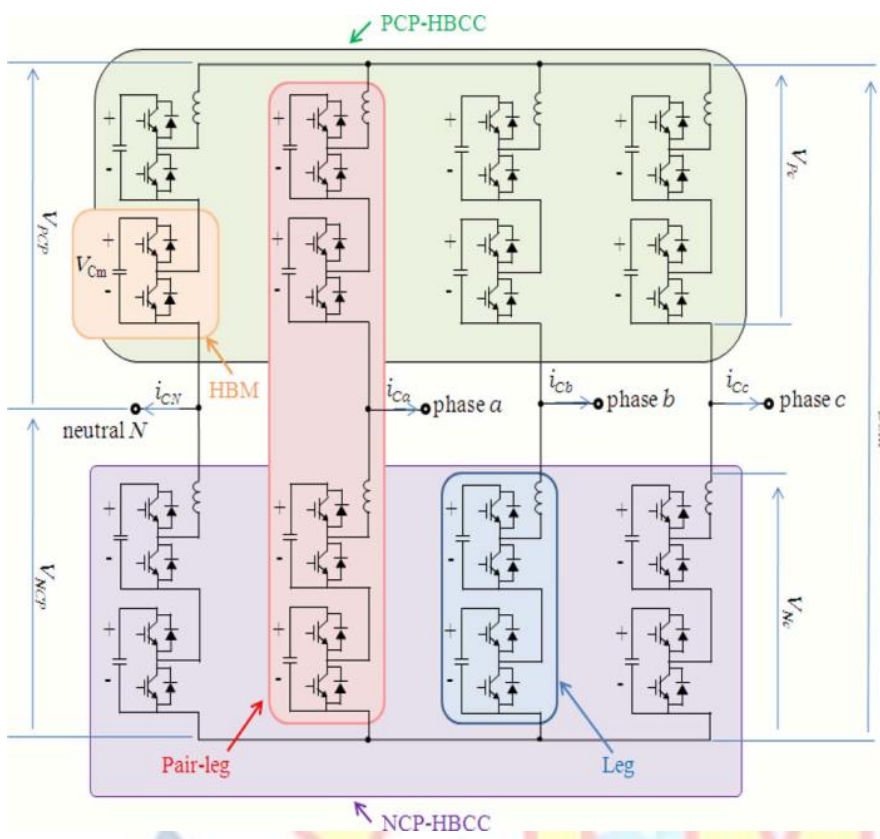

Fig 2: H-BRIDGE model

\section{Fuzzy Logic:}

Fuzzy theory was initiated by Lotfi A. Zadeh in 1965 as an extension of the classical control theory. According to him classical control theory put too much emphasis on precision and therefore could not the complex systems. Later he formalized the ideas into the paper "Fuzzy set." Fuzzy sets are sets whose elements have degrees of membership.

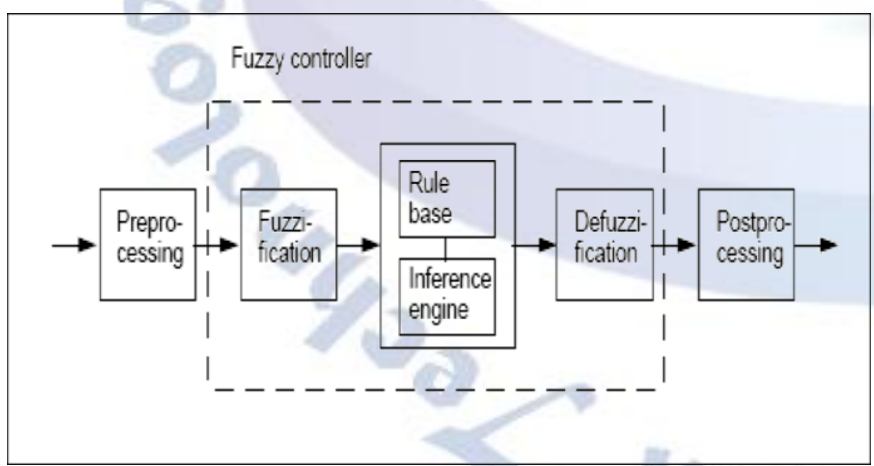

Figure 3 Structure of fuzzy logic controller

\section{Application Area of Fuzzy Logic:}

1: Controller application

2: Communication engineering

3: Image processing

4: Production engineering

5: System identification

\section{H-BRIDGE-BASED STATCOM}

Here the H-BRIDGE-based STATCOM is proposed for full compensation of the MV-LC loads such as electric traction systems. The suggested high power STATCOM comprises of two or more identical H-BRIDGE all connected in parallel. A simple model of the STATCOM, having two H-BRIDGE, is shown in Fig. 6. While all H-BRIDGE have the same electrical specification, all NCP legs connected together, and the same is done for all PCP legs to achieve a better voltage regulation for the capacitors. Hence, voltage regulation for the HBM capacitors is managed without any additional connections or energy transfer circuits

\section{A. Switching Modulation of the EH-BRIDGE}

Considering the discussed current sharing for the H-BRIDGE-based STATCOM, (3) has to be rewritten in order to calculate the instantaneous reference voltages for each leg $\left(\mathrm{V}_{\mathrm{Nx}}\right.$ and $\left.\mathrm{V}_{\mathrm{Px}}\right)$ of the STATCOM containing parallel H-BRIDGE as follows:

$$
\left[\begin{array}{l}
V_{N x-r e f} \\
V_{P x-r e f}
\end{array}\right]=\left[\begin{array}{l}
V_{x}-L_{F} \frac{\left(i_{C x-r e f}-m_{i} C_{C x}\right) f_{S C}}{2 m}+\frac{V_{D C M}}{2} \\
V_{x}-L_{F} \frac{\left({ }_{i} C x-r e f-m i C_{x}\right) f_{S C}}{2 m}-\frac{V_{D C M}}{2}
\end{array}\right]
$$

The reference voltages obtained by (10) is identical for all corresponding legs of each H-BRIDGE. A phase-shift PWM modulation technique, similar to that of the H-BRIDGE-based STATCOM, can be applied to the EH-BRIDGE. There-fore, the switching pattern for each HBM is obtained by comparing the general reference voltage with the carrier signal of each HBM as shown in Fig. 3. Carrier signals used for all shunted H-BRIDGE are relatively shifted to each other lower the output current ripple of STATCOM as follows:

$$
\tau=\frac{1}{f_{c 1} n m}
$$

Where $\tau$ is the time interval between two adjacent carrier signals, $\mathrm{f}_{\mathrm{C} 1}$ is the carrier frequency, $\mathrm{n}$ is the number of HBM in each leg, and $m$ is the number of H-BRIDGE in the STATCOM.

\section{SIMULATION DIAGRAM AND RESULTS}

The simulation is done based on the figure 1 . The simulation diagram for the proposed grid interfaced wind energy system with STATCOM is shown in figure 4. 


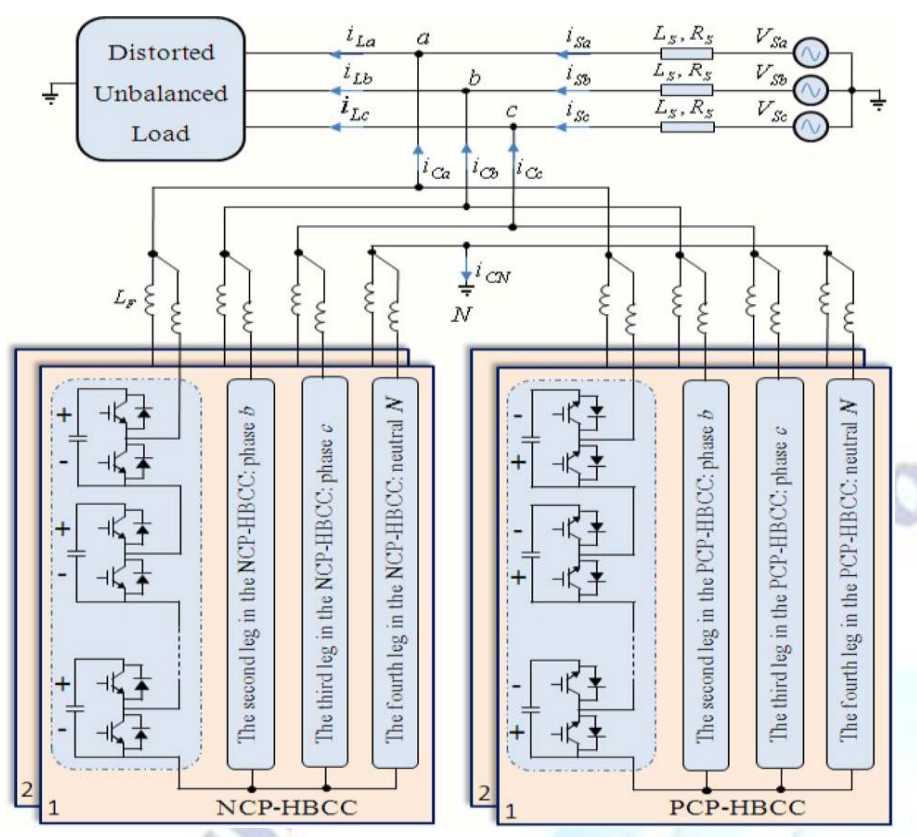

Fig 4: Basic Diagram for H-BRIDGE based STATCOM

Simulations were carried out using PSIM, while the control algorithm was managed with MATLAB; then, they were linked together using SIMCOUPLER of the PSIM. Assume that a $25-\mathrm{kV}$ network is supplying a distorted unbalanced load in an electrical railway application. The load is coupled across two phases of the PCC. Spectral of the load current, shown in Fig. 4, introduces a total harmonic distortion (THD) of $18.27 \%$. Sep-arate simulations were arranged for both the H-BRIDGE and the H-BRIDGE-based STATCOM for a power rating of \pm 15 MVA. Each leg of the two compensators has 22 cascaded HBM. All HBM have a dc-link capacitor with a nominal dc voltage of $3.3 \mathrm{kV}$.

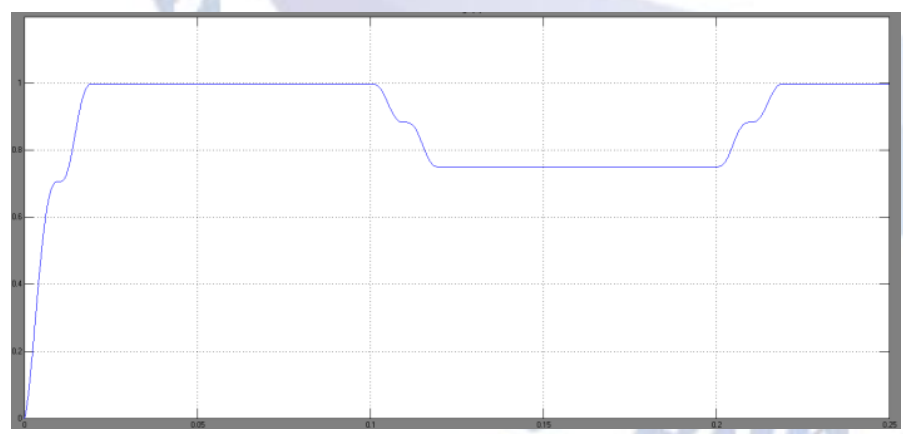

Figure 5: Simulation Result for Line Voltage under RMS without DSTATCOM

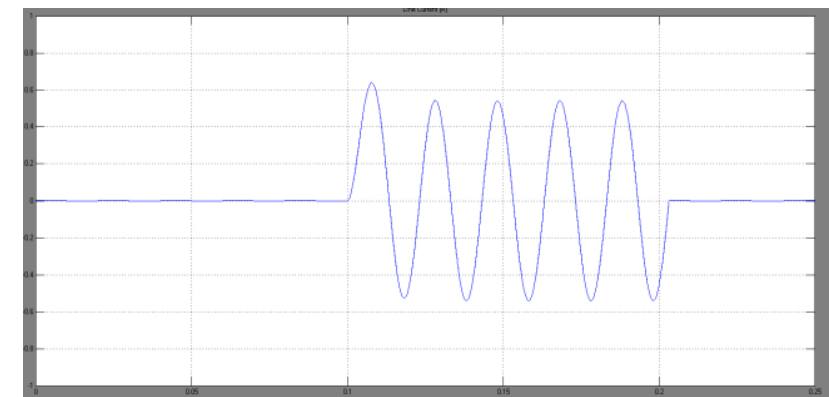

Figure 6: Simulation Result for Line Current under RMS without DSTATCOM

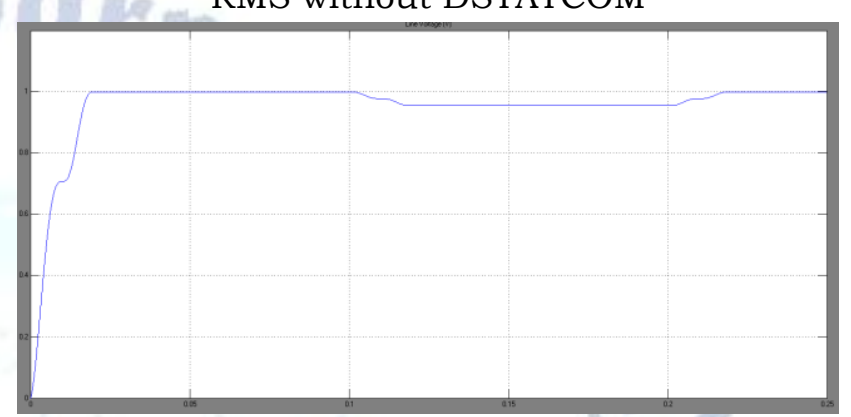

Figure 7: Simulation Result for Line Voltage under RMS with DSTATCOM

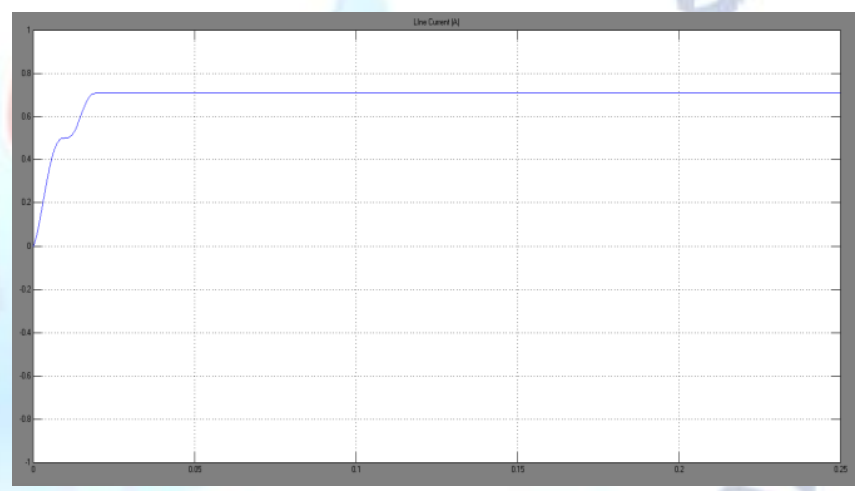

Figure 8: Simulation Result for Line Current under RMS with DSTATCOM

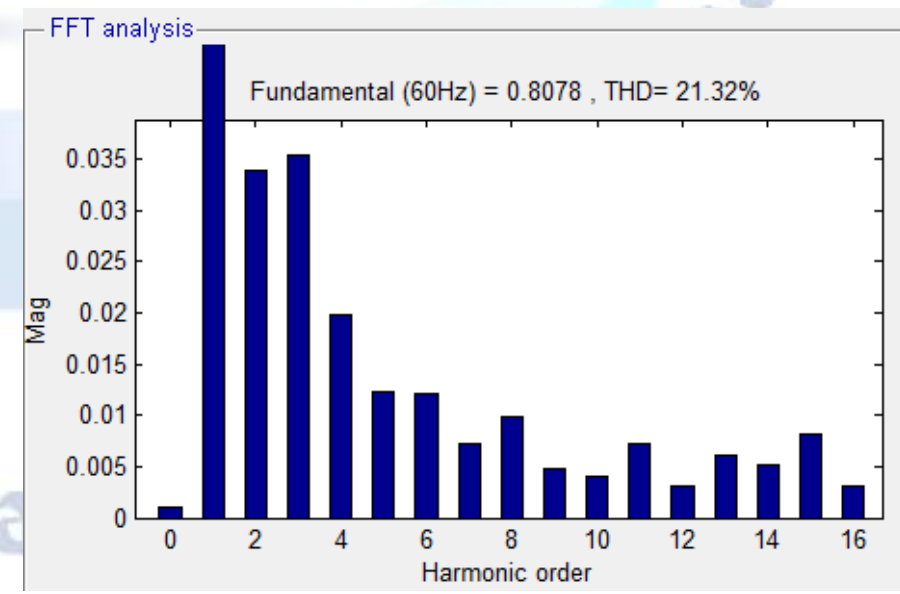

Figure 9: THD value for Line Current without FUZZY 


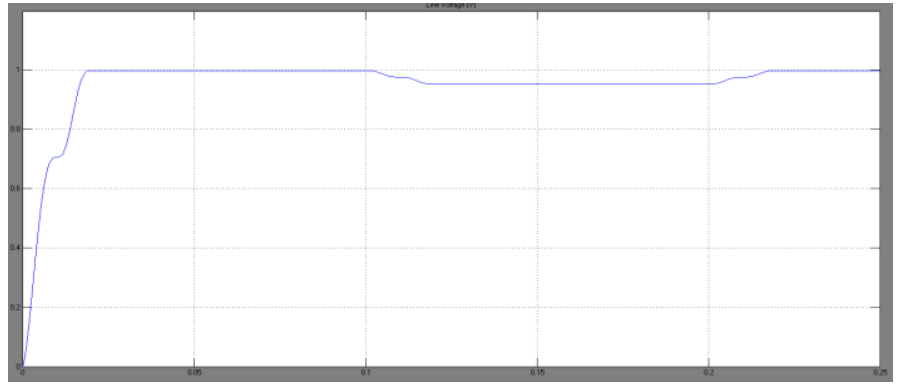

Figure 10: Simulation Result for Line Voltage under RMS with DSTATCOM and FUZZY

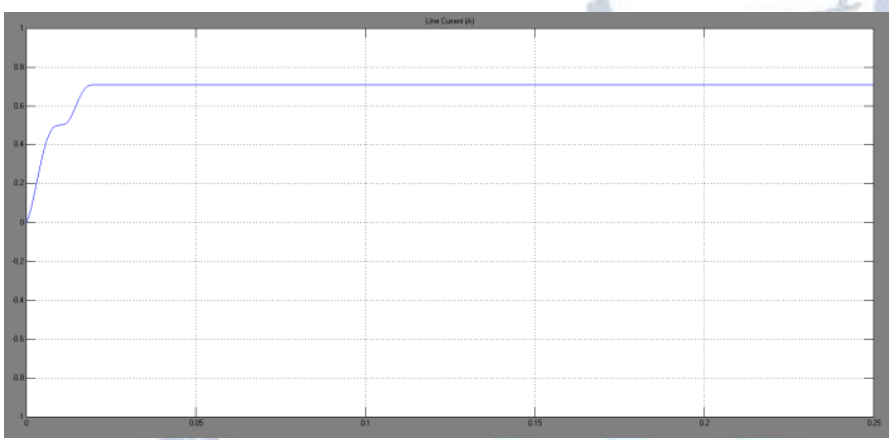

Figure 11: Simulation Result for Line Current under RMS with DSTATCOM and FUZZY

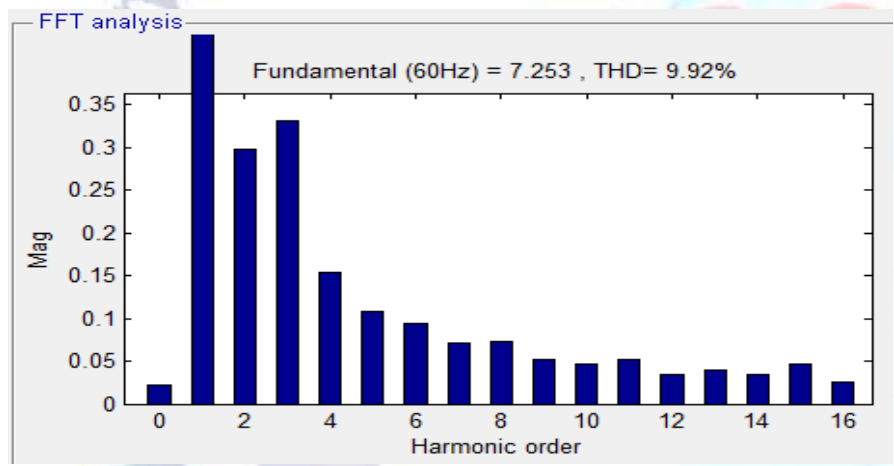

Figure 12: THD value for Line Current with FUZZY

\section{v. CONCLUSION}

This paper proposes a novel type of Fuzzy based STATCOM for a full compensation of unbalanced and distorted nonlinear load in the MV-LC networks under the presence of both the load and the source harmonics. This modular Fuzzy based STATCOM introduces a transformerless design, employing several isolated units composed of a number of cascaded HBM. Then, this STATCOM is developed by paralleling a number of H-BRIDGE to achieve higher efficiency, higher reliability, lower weight and size, lower switching frequency and lower ratings for the switches. Various control strategies are suggested for both H-BRIDGE and the H-BRIDGE in order to generate the reference currents for the compensator, followed by another strategy to get their corresponding reference voltages. Another controller i.e, Fuzzy is responsible for regulating all dc-link capacitor voltages at a predetermined level. Simulations results were arranged for both the H-BRIDGE and Fuzzy based STATCOM.

\section{REFERENCES}

[1] P.-C. Tan, R. E. Morrison, and D. G. Holmes, "Voltage form factor control and reactive power compensation in a $25-\mathrm{kV}$ electrified railway system using a shunt active filter based on voltage detection," IEEE Trans. Ind.Appl., vol. 39, no. 2, pp. 575-581, Mar./Apr. 2003.

[2] M. T. Bina and M. D. Panahlou, "Design and installation of a $250 \mathrm{kVAr}$ D-STATCOM for a distribution substation, "Elsevier: Electric Pow. Syst.Res., vol. 73, no. 3, pp. 383-391, Apr. 2005.

[3] F. Z. Peng and J. Wang, "A universal STATCOM with delta-connected cascade multilevel inverter," inProc. 35th Annu. IEEE Pow. Electron. Spec. Conf., Aachen, Gennany, Jun. 2004, pp. 3529-3533.

[4] R. E. Betz, T. Summerst, and T. Furney, "Using a cascaded H-bridge STATCOM for rebalancing unbalanced voltages," inProc. 7th Int. Conf. Pow. Electron., Daegu, Korea, Oct. 2007, pp. 1219-1224.

[5] F. Z. Peng, J. Wang, McKeever, and D. J. Adams, "A power line conditioner using cascade multilevel inverters for distribution systems," IEEE Trans. Ind. Appl., vol. 34, no. 6, pp. 1293-1298, Nov./Dec. 1998.

[6] H. Akagi, S. Inoue, and T. Yoshii, "Control and performance of a transformerless cascade PWM STATCOM with star configuration," IEEE Trans. Ind. Electron., vol. 43, no. 4, pp. 1041-1049, Jul./Aug. 2007.

[7] C. K. Lee, J. S K. Leung, S. Y R. Hui, and H. S. H. Chung, "Circuit-level comparison of STATCOM technologies," IEEE Trans. Pow. Electron.,vol. 18, no. 4, pp. 1084-1092, Jul. 2003.

[8] R. E. Betz, T. Summers, and T. Furney, "Symmetry compensation using an H-bridge multilevel STATCOM with zero sequence injection," in Proc. Ind. Appl. Conf., Oct. 2006, pp. 1724-1731.

[9] H. M. Pirouz and M. T. Bina, "New transformerless STATCOM topology for compensating unbalanced medium-voltage loads," inProc. 13th Eur. Conf. Pow. Electron. Appl., Barcelona, Spain, Sep. 2009, pp. 1-9.

[10] R. Marquardt, "Stromrichters chaltungen mitverteilten Energiespeichern," German Patent DE 10103 031, Jan. 24, 2001.

[11] S. Rohner, S. Bernet, M. Hiller, and R. Sommer, "Modulation, losses and semiconductor requirements of modular multilevel converters," IEEE Trans. Ind. Electron., vol. 57, no. 99, pp. 2633-2642, Aug. 2009.

[12] J. Rodr'iguez, S. Bernet, B. Wu, J. O. Pontt, and S. Kouro, "Multi-level voltage-source-converter topologies for industrial medium-voltage drives," IEEE Trans. Ind. Electron., vol. 54, no. 6, pp. 2930-2945, Dec.2007.

[13] C. D. Schauder, "Advanced static var compensator control system," U.S.Patent 5329 221, Jul. 12, 1994.

[14] M. T. Bina and A. K. S. Bhat, "Averaging technique for the modeling of STATCOM and active filters, "IEEE Trans. Pow. Electron., vol. 23, no. 2, pp. 723-734, Mar. 2008.

[15] M. Hagiwara and H. Akagi, "Control and experiment of pulse-width-modulated modular multilevel converters, "IEEE Trans. Pow. Electron., vol. 24, no. 7, pp. 1737-1746, Jul. 2009.

[16] H. Akagi, E. Watanabe, and M. Aredes, Instantaneous Power Theory and Applications to Power Conditioning. Hoboken, NJ: Wiley, 2007. 